\title{
Quality Management System at NPLI: Transition of ISO/IEC 17025 From 2005 to 2017 and Implementation of ISO 17034: 2016
}

\author{
G. Mandal* ${ }^{\mathbb{D}}$, M. A. Ansari and D. K. Aswal \\ CSIR - National Physical Laboratory (NPLI), Dr. K. S. Krishnan Road, New Delhi 110 012, India
}

Received: 27 March 2021 / Accepted: 12 June 2021 / Published online: 24 July 2021

(C) Metrology Society of India 2021

\begin{abstract}
ISO/IEC 17025 is the single most popular and well adopted international standard which is applicable for any testing and calibration laboratories irrespective of size of the laboratories. Similarly, ISO 17034 is also very important international standard for development/production of reference materials (RMs) by competent producers. CSIR-National Physical Laboratory of India (NPLI) was one of the 38 National Metrology Institutes (NMIs) those who signed International Committee for Weights and Measures Mutual Recognition Arrangement (CIPM MRA) during 21st General Conference on Weights and Measures (CGPM) meeting in Paris, France on 14th October, 1999. NPLI has been maintaining quality system based on ISO/IEC 17025 for more than two decades to fulfil the requirements of CIPM MRA. NPLI has participated in 130 international inter-comparisons so far; some of them were also piloted by NPLI. NPLI has also undergone International Peer Reviews through Asia Pacific Metrology Programme (APMP) to register 236 Calibration and Measurement Capabilities (CMCs) on various parameters in International Bureau of Weights and Measures Key Comparison Database (BIPM KCDB). However, NPLI for the first time implemented uniform quality system based on ISO 17034 in 2020. In this direction, NPLI for the first time prepared integrated Quality Manual to make policies, objectives and procedures addressing all the requirements of both the standards. Presently, 28 Sub-Divisions of NPLI follow quality system. Some of the Sub-Divisions are involved only in calibration/testing activities maintain only ISO/IEC 17025: 2017. Similarly, some of the Sub-Divisions are involved only in development/production of RMs/certified reference materials (CRMs) (Bharatiya Nirdeshak Dravya, BND ${ }^{\circledR}$-Indian Reference Material) maintain only ISO 17034. On the other hand, few Sub-Divisions are involved both in calibration/testing as well as BND activities and accordingly follow both the standards. It is an extraordinary challenge for implementation and monitoring of quality system in such a big organization like NPLI. In this article, authors have highlighted preparation process of integrated quality manual based on ISO/IEC 17025: 2017 and ISO 17034: 2016 including policies, objectives \& procedures adopted and its implementation process at NPLI. In November, 2020, NPLI has undergone on-site peer review of quality system of 23 Sub-Divisions through APMP.
\end{abstract}

Keywords: Metre convention; CIPM MRA; ISO/IEC 17025: 2017; ISO 17034: 2016; Quality system; NMI; Peer review

\section{Introduction}

ISO/IEC 17025 is the single most important and popular standard for calibration and testing laboratories around the world. In November 2017, ISO/IEC 17025: 2017 standard has been issued superseding 2005 version in accordance with advancement in science and technologies and to meet the demand of modern industries. As per the initial guidelines issued by the ISO, the transition of ISO/IEC 17025 from 2005 to 2017 was to be completed within 3

*Corresponding author, E-mail: goutam@nplindia.org years i.e., by November 2020. Although due to COVID-19 pandemic outbreak and prevailing situations, ISO has later extended transition date up to 01st June 2021 [1].

NPLI has successfully completed transition process of Quality Management System (QMS) in accordance with ISO/IEC 17025: 2017 as per pre-determined schedule in October 2020. NPLI had started the program of production/ development of Bharatiya Nirdeshak Dravya $\left(\mathrm{BND}^{\circledR}\right)$-Indian Reference Material long back in 1980s for import substitution. However, it has progressed exponentially in recent years. Earlier, NPLI didn't have any Quality Manual based on ISO 17034 containing common policies, procedures and uniform formats for entire laboratory, therefore, 
various Sub-Divisions involved in BND activities followed this standard of their own.

This is the first time, NPLI has prepared integrated Quality Manual addressing all the requirements of both ISO/IEC 17025: 2017 and ISO 17034: 2016 standards $[2,3]$ and successfully implemented the same in October 2020. In November 2020, NPLI has for the first time undergone peer review of Quality System of 23 SubDivisions through APMP based on both the standards. There was no non-compliance during on-site assessment. The final report is under APMP peer review process.

\section{The Metre Convention}

A historic diplomatic treaty was signed among seventeen nations in Paris on 20th May 1875 for uniform measurement system. This treaty is known as "The Metre Convention". This treaty created the International Bureau of Weights and Measures (BIPM), an intergovernmental organization under the authority of the General Conference on Weights and Measures (CGPM) and the supervision of the International Committee for Weights and Measures (CIPM). The uniform measurement system is implemented through Regional Metrology Organizations (RMOs) broadly based on continent and National Metrology Institutes (NMIs) in every member state. The detail description of the Metre convention, roles of CGPM, CIPM, BIPM, RMOs, NMIs, etc., are given in [4-7]. However, for the completeness of this article, the international measurement structure is depicted using Fig. 1.

\section{Role of CIPM MRA}

The CIPM MRA was signed by the Directors of 38 NMIs and 2 international organizations during 21st CGPM meeting at BIPM in Paris, France on 14th October 1999. The main objectives of the MRA are to establish the degree of equivalence of national measurement standards maintained by NMIs and to provide the mutual recognition of calibration and measurement certificates issued by NMIs [8]. It also helps to facilitate cooperation between laboratories and other bodies by generating wider acceptance of results between countries. Calibration certificates and test reports can be accepted from one country to another without the need for further calibration/testing, which, in turn, improves international trade.

\section{Peer Review Process}

The NMIs go through the rigorous process of international peer review for recognition of QMS and technical competence. This includes on-site peer review of QMS and technical competence through respective RMO. These peer review reports are further reviewed through intra-RMO and inter-RMOs. After satisfactory completion of review, final approval is given by Joint Committee of the RMOs and the BIPM (JCRB) and CMCs are registered in BIPM KCDB.

There are six RMOs recognized under the framework of CIPM MRA [9]. These RMOs are as follows:

AFRIMET: Intra-Africa Metrology System; APMP: Asia Pacific Metrology Programme;

COOMET: Euro-Asian Cooperation of National Metrological Institutions;

EURAMET: European Association of Metrology Institutes;

GULFMET: Gulf Association for Metrology; and

SIM: Inter-American Metrology System.

\section{Degree of Equivalence of Measurement System Through CMCs}

There are four pillars i.e., metrology/measurement, documented standards, legal metrology and accreditation which indicates the quality infrastructure and quality of human lives of a country. NPLI has been playing one of the most important roles by maintaining national standards of measurements (except ionizing radiation) for last 74 years (NPLI has celebrated 75th Foundation Day on 4th January 2021) and also by directly/indirectly supporting other three pillars.

CMCs of an NMI are the indicators of quality infrastructure (QI) of a country in terms of competency of personnel, equipment and other facilities available, infrastructure, measurement traceability, methods used, results of international inter-comparisons and many more. Number of CMCs registered in BIPM KCDB as well as number of parameters including range is other parameter to judge the QI of a country. Quantum of each CMC is supported by international inter-comparisons participated by that NMI to establish the degree of equivalence in measurement system.

NPLI has successfully registered 236 CMCs in BIPM KCDB and participated in 130 international inter-comparisons in various parameters. However, number of $\mathrm{CMCs}$ are quite less as compared to other leading NMIs and need to be increased. NPLI has planned to add more than 100 new CMCs in addition to $236 \mathrm{CMCs}$ as well as to improve the existing CMCs through upcoming technical peer 


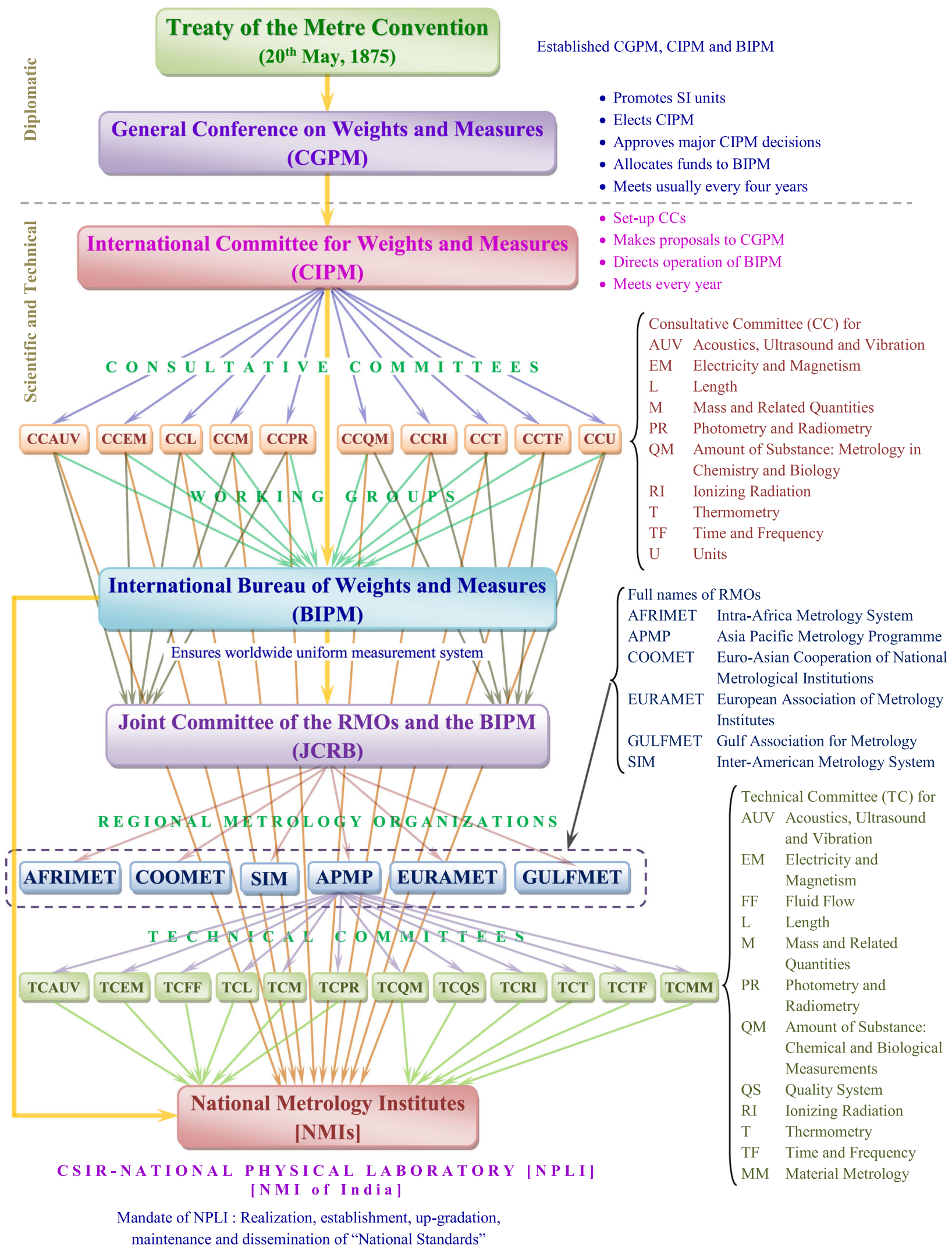

Fig. 1 International agreement on metrology for ensuring a single, coherent system of measurements traceable to SI units throughout the world 
Fig. 2 Degree of equivalence in measurement standards among NMIs

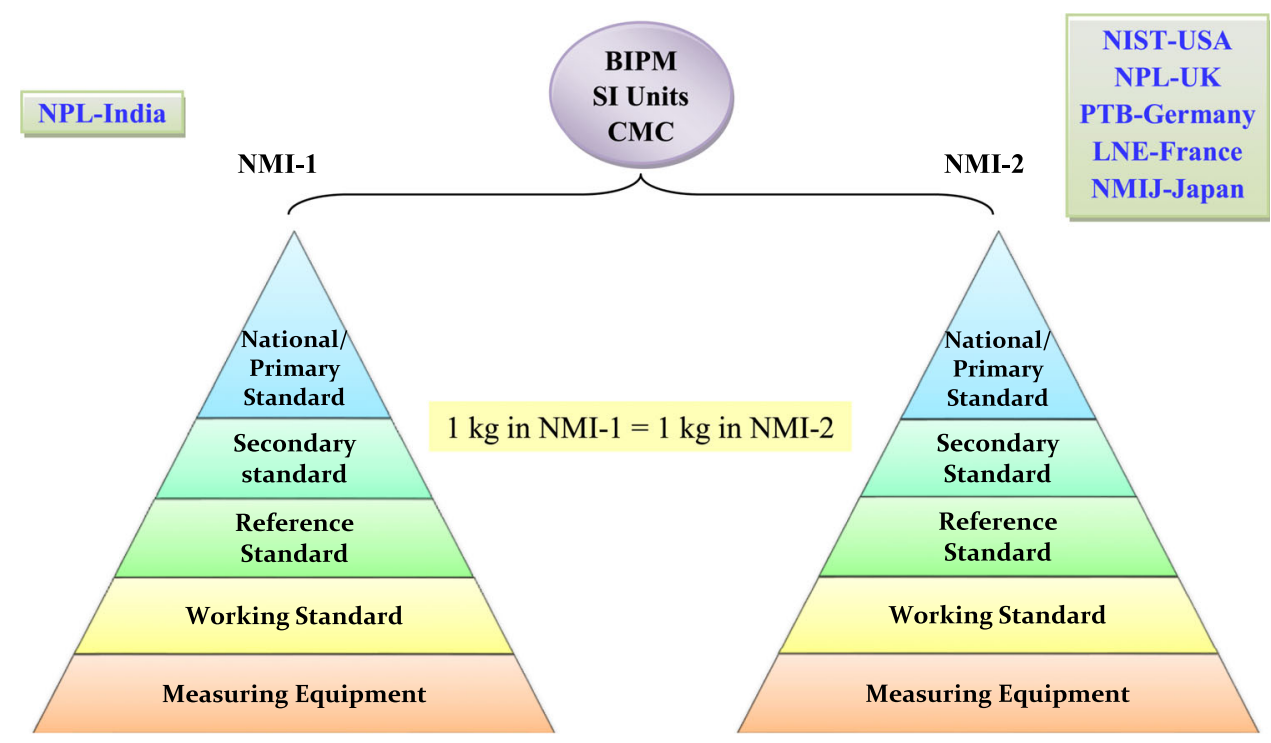

reviews. An illustration of degree of equivalence in measurement standards among NMIs is shown in Fig. 2.

\section{Role of NPLI as NMI of India}

The CSIR-NPL is one of the oldest national laboratories and was set up under the Council of Scientific and Industrial Research (CSIR) on 4th January, 1947. As per Weights and Measures Act and its associated Legal Metrology (National Standards) Rules, the main responsibility of CSIR-NPL is the realization, establishment, custody, maintenance, dissemination, reproduction and updating of "National Standards" of measurement [10, 11]. The objective of the laboratory is to strengthen and advance physics and chemistry based R\&D for the overall development of science and technology in the country.

It is the apex laboratory for calibration, testing and BND activities in the country. It is designated as the NMI of India and identified as CSIR-National Physical Laboratory of India (NPLI) in BIPM.

Being NMI of India, the then Director of NPLI, Dr. K. S. Krishnan signed the "Metre Convention" on behalf of Government of India, and 'the Republic of India' became a Member State in 1957. India is one of founder members of APMP (RMO for India) since 1977 [12]. NPLI represent India in APMP every year in policy making decision related to improvement of quality infrastructure through measurements. India is also one of the founder signatories of the CIPM MRA. In the same way, on behalf of Government of India, the CIPM MRA was signed by the then Director of NPLI, Dr. A. K. Raychaudhuri at BIPM in Paris, France on 14th October, 1999 [4-6].
In view of the above, the NPLI has implemented QMS, encompassing quality system and technical capabilities, based on ISO/IEC 17025: 2017 and ISO 17034: 2016 in respective metrological activities to demonstrate quality system and technical competence at the international level.

\section{Role of QMS of NPLI in Development of Quality Infrastructure of India [13]}

QMS has been playing a pivotal role for maintaining Quality System of NPLI for reporting valid measurement results and production/development of BNDs. Effectiveness of implementation of Quality System is monitored in all the Sub-Divisions covered under QMS through annually conducted internal audits and management review (known as Steering Committee). Additional internal audits are also conducted for the respective technical Sub-Division before going for international peer review.

Being NMI, the quality system and technical competency of NPLI are evaluated by international experts through APMP. As per CIPM MRA guidelines, there are three pathways to demonstrate the same [14].

(a) Third party accreditation (technical assessors must meet criteria given for technical peers); or

(b) Certification to ISO 9001 and attestation by technical peers; or

(c) Attestation by a team consisting of quality system experts and technical peers.

NPLI follows 'Pathway C' for peer review. QMS organizes all the necessary arrangements of international peer review (both Quality and Technical) through APMP. APMP monitors the activities of NMIs through various 
technical committees by presentation of annual report and discussion in APMP annual meetings. QMS represents India in Technical Committee for Quality System (TCQS) in the discussion of quality infrastructure among various countries within the APMP region.

As per the APMP guidelines [15] and keeping in view of COVID-19 pandemic situation, NPLI has undergone onsite peer review of quality system of 23 Sub-Divisions through APMP in November, 2020. Technical peer review will be conducted separately.

As per Gazette Notification 2758, Part II, Sect. 3, Subsection (ii) dated 22nd August, 2019 of Ministry of Environment, Forest and Climate Change, Government of India has designated CSIR-NPL (NPLI) as national verification agency for certifying instruments and equipment for monitoring emissions and ambient air. NPLI is in the process of developing testing and certification facilities for certification of Continuous Ambient Air Quality Monitoring Station (CAAQMS) and Online Continuous Emission Monitoring Systems (OCEMS), conforming to ISO/IEC 17025: 2017 and ISO/IEC 17065: 2012. Quality Manual as per the requirements of ISO/IEC 17065: 2012 is under preparation and will be implemented soon.

Bhabha Atomic Research Centre (BARC) is recognized as Designated Institute (DI) of India for Ionizing Radiation since 2003 on the recommendation of NPLI as NMI. As per the Memorandum of Understanding (MoU) signed between two organizations in October 2020, NPLI is supporting BARC for establishing QMS based on ISO/IEC 17025: 2017 and for international peer review to get the CMCs registered on ionizing radiation in BIPM KCDB [16].

NPLI is not only maintains and disseminates national standards of measurements, but also disseminates knowledge through training programmes, invited lectures, etc. NPLI has also been providing one year full time Post Graduate Diploma (PGD) Course on 'Precision Measurement and Quality Control (PMQC)' under the Academy of Scientific and Innovative Research (AcSIR) to provide skilled manpower to the accredited laboratories, industries, etc., in line with Government of India's skill development programme. QMS of NPLI offers one of the subjects i.e., 'Quality Control and Management', which covers requirements of ISO/IEC 17025, ISO 17034, etc., auditing techniques, techniques for quality control, proficiency testing, inter-laboratory comparison (ILC), control charts, etc., in one semester in this course $[2-4,17]$.

Consequent upon above, NPLI QMS's activities are not restricted for maintaining quality system within the organization, it also contributes toward development, improvement and strengthening of quality infrastructure of India.

\section{Preparation Process of Integrated Quality Manual}

On the onset of the preparation of Quality Manual, two independent core committees were constituted by the Director, one for ISO/IEC 17025: 2017 and other for ISO 17034: 2016. The committee members were selected from various divisions to incorporate the opinions of activities under QMS. Initially QMS studied both the standards meticulously and prepared a comparative chart of each clause/sub-cause based on common as well as specific requirements of these two standards.

Numbers of meetings were held independently among members of each committee for preparation of initial drafts of Quality Manual. After completion of initial drafts, combined meetings of both the committees were held to integrate the policies, objectives and procedures. The draft of integrated quality manual was circulated and discussed with Director, all the Heads of Divisions and Sub-Divisions for their valuable remarks and suggestions for further improvements. These remarks and suggestions were further thoroughly discussed among the committee members before finalizing the final draft. The final draft was approved by and issued under the authority of Director, NPLI and distributed to all the authorized personnel as per distribution list for implementation.

\section{Policy of NPLI Related to QMS Based on ISO/IEC 17025: 2017 and ISO 17034: 2016 [2, 3]}

\subsection{Clause 4-General requirements}

NPLI management is fully committed to impartiality and ensures it through quality policy, organizational structure, operational and quality driven objectives and goals. Every year, all the staff mandatorily take "Integrity Pledge" during "Vigilance Awareness Week" and submit to Vigilance Section of NPLI for further submission to Central Vigilance Commission, Government of India. The managerial and technical personnel of the calibration/testing/ BND activities are free from any undue internal and external commercial, financial and any other influences, which adversely affect the quality of the work. To maintain impartiality, same methods are followed for all the customers (both internal and external) to provide calibration/ testing services and calibrations/tests performed by a person are always crosschecked by another person in same field. All the calibration certificates/test reports are signed by at least two technical persons including respective Head, Sub-Division which is issued by the Head, CFCT (role of CFCT is described in 9.4) as Director's nominee. Nevertheless, whenever risk to impartiality is identified by any means, appropriate actions, which deemed fit, are taken to 
eliminate or minimize the risk and the effectiveness of actions taken is monitored.

NPLI maintains confidentiality of all the information and data obtained from the customers/users. In case if it is required to release confidential information by law or authorized by contractual arrangement, guidelines of Government of India and CSIR are followed.

\subsection{Clause 5-Structural requirements}

NPLI is designated as NMI of India by an act of Parliament and its associated rules of legal metrology for the realization, establishment, custody, maintenance, determination, reproduction and updating of "National Standards" of the physical parameters except ionizing radiation.

NPLI has well established structure for implementing QMS based on both the standards. As per the structure, the Director is the overall in-charge for scientific \& technical operations and generating resources for the implementation of the QMS. Head, Divisions are responsible for smooth running of the scientific and technical operations of their respective Division. They are also responsible for the future planning of scientific and technical requirements. Under each Division, there are various Sub-Divisions headed by Head, Sub-Divisions. Head, Sub-Divisions are responsible for supervision, maintenance, up-gradation, dissemination and R\&D of the various metrological activities dealt in their Sub-Divisions as well as for creating awareness about QMS among their staff members. Quality Manager is responsible for the monitoring of implementation of QMS as per ISO/IEC 17025: 2017 and ISO 17034: 2016 in respective Sub-Division through evaluation of internal audit reports, corrective actions taken by respective Sub-Division, discussions held and decisions taken in steering committee meetings, follow-up actions, etc. Quality Manager has direct access to the Director. In absence of the Director/Quality Manager/Head, Division/ Head, Sub-Division, their deputy performs their functions. Interrelationships among the personnel within the laboratory are demonstrated through organizational structure as given in Fig. 3.

\subsection{Clause 6-Resource requirements}

All the personnel engaged in calibration/testing/BND activities are permanent employee and competent based on the requirements of education, qualification, training, technical knowledge, skills and experience. Management provides specific training, both on quality system and technical parameters, to the staff, whenever required or available for development of knowledge/skill.

Most of the metrological activities are carried out in controlled environmental conditions in dedicated Apex
Metrology Laboratory (AML). AML building is exclusively designed and built with effective separation between each activity for environmental stability, protections from electromagnetic interference, sound, vibration, contamination, etc. However, some of the metrological activities are carried out in various satellite buildings under controlled environmental conditions and fulfilling other technical requirements.

NPLI is well equipped with state-of-the-art facilities for carrying out calibration/testing/BND activities under the scope of the laboratory. In general, as per policy, NPLI uses its own equipment/reference standards/reference materials. However, in any exceptional case of on-site calibration/testing, equipment can be used outside its permanent control with prior permission of the competent authority fulfilling the requirements of relevant technical standards. Performance of each equipment affecting the measurement results is evaluated by the respective technical Sub-Division and all the technical records are maintained by them.

Being NMI of India, NPLI maintains "National Standards" of measurements. The national/primary standards are either established/realized at NPLI itself and validated through inter-comparisons or get calibrated from BIPM or any other leading NMIs. NPLI maintains various other levels of standards depending on the parameters those are directly/indirectly traceable to national/primary standards through an unbroken chain and used for the calibration/ testing of the various instruments/items received from customers. The traceability of the property value of BND is achieved through calibration/testing following primary method/using CRMs linking to SI units or through international inter-comparisons organized by BIPM, APMP, etc.

NPLI purchases all the products such as measurement standards, equipment, reference materials, consumables, etc., and services such as calibration \& testing services, facility \& equipment maintenance services, etc., from the reputed suppliers/manufacturers/providers through purchase section, following prevailing rules and procedures of Government of India and CSIR.

\subsection{Clause 7-Process requirements}

Centre for Calibration and Testing (CFCT) is customers' interface and takes care of all kinds of administrative matters related to calibration/testing/BND activities. These include charges, receiving, handling, returning/disposing of calibration/test items, selling of BNDs, hand over/dispatch of certificates/reports, etc. NPLI provides calibration/testing services in various parameters, hence, it is quite difficult task for CFCT to verify all the items during receiving if these items are meeting the necessary requirements. 


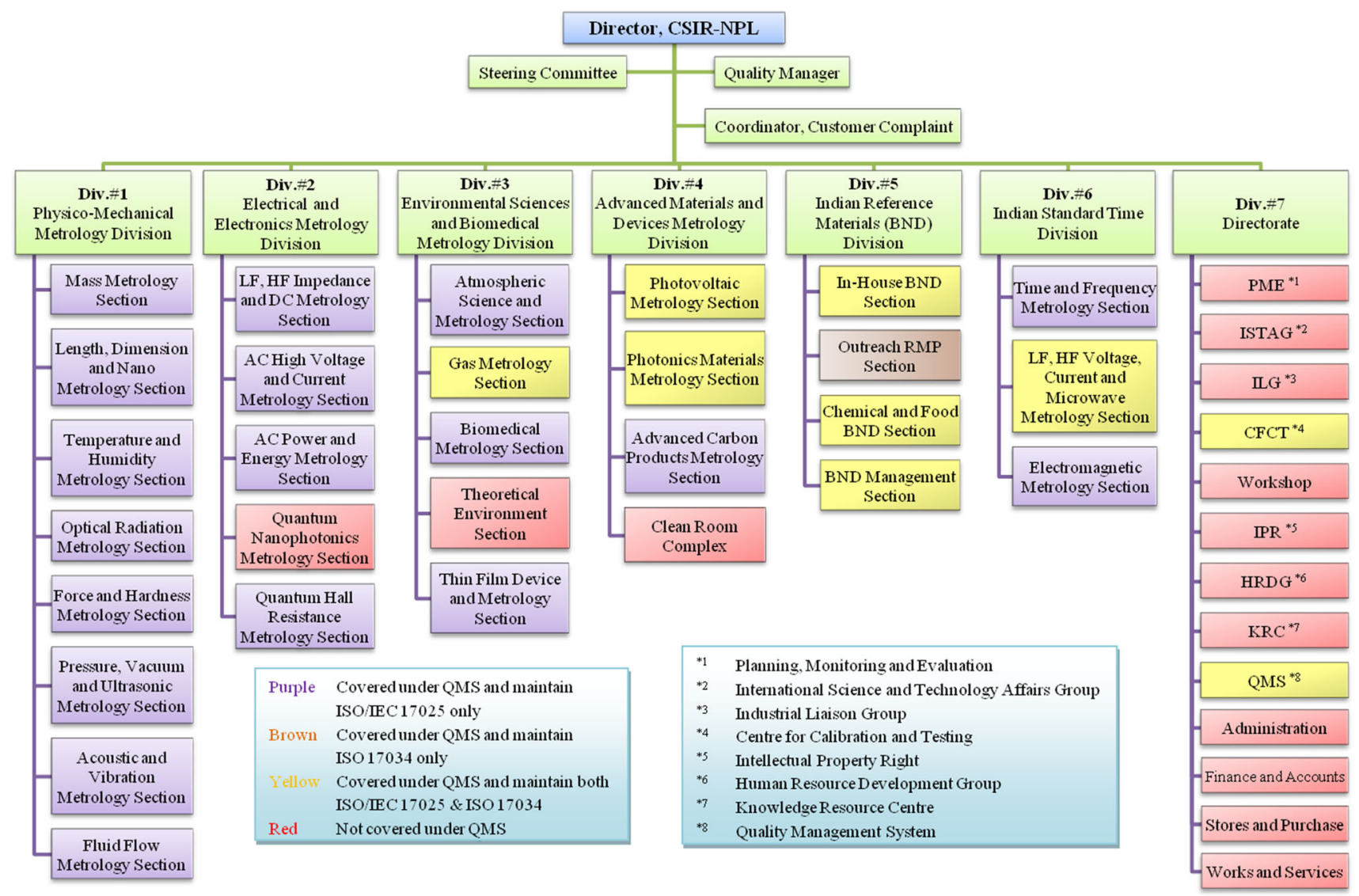

Fig. 3 Organization structure of NPLI including Sub-Divisions covered under QMS

Therefore, items are received in respective technical SubDivision by competent personnel providing limited access to the customers. All calibration/testing services and BNDs offered by the NPLI are readily available on its official website (www.nplindia.in).

In general, NPLI uses methods published in international/national standards, reputed journals, books, etc., for calibration/testing/BND activities. In case of any non-standard/laboratory-developed methods and standard methods used outside the intended scope, the methods are validated by the competent scientists prior to apply. For all the measurements, significant factors are identified and taken into account for the evaluation of measurement uncertainty, following the relevant technical standards as well as Guide to the expression of Uncertainty in Measurement (GUM) document.

As per the policy, NPLI does not undertake sampling activity related to calibration/testing. However, for the development/production of BNDs, sampling activities are undertaken, whenever required, based on the laid down procedure.

All the technical records related to calibration/testing/ BND activities including observations, results, reports, environments, factors affecting the measurement result and its associated uncertainty, etc., are taken care and maintained in respective technical Sub-Division.

NPLI participates in key/supplementary/pilot/bilateral comparisons with other leading NMIs in various parameters conducted by BIPM, APMP, etc., to support CMCs. NPLI has participated in 130 international inter-comparisons so far; some of them were also piloted by NPLI.

For uniform reporting of results, format of calibration certificate/test report is provided in Quality Manual. These formats carry 9 points such as customer's name and address, description of instrument, environmental conditions, traceability of standard(s) used, principle/methodology used, measurement results, date(s) of calibration/ testing, etc. Any additional information like decision rules, opinions \& interpretations, etc., are provided in remarks column. NPLI provides the statement of conformity only when it is inherent in the international/national standards and/or regulatory documents. Hence, risk is covered in the respective technical standard. Keeping in view about awareness regarding calibration/testing among the countrymen and being an NMI of the country, all the calibration certificates carry recommendation date of next calibration based on various factors of instruments/artefacts. 
NPLI has documented process for handling of customer complaints. NPLI has a Coordinator Customer Complaints for handling the complaints, taking appropriate actions to resolve them and communicating the status to the complainants.

Whenever nonconforming work is identified, appropriate action is taken immediately as per the laid down procedure to eliminate or mitigate it. Thorough evaluations are done before resumption of work. In case evaluation indicates that the non-conformance could recur necessary corrective actions are taken.

At present, laboratory information management system (LIMS) is managed and maintained in-house for the collection, processing, recording, reporting, storage or retrieval of data. All the data, either soft copy or hard copy, are kept secured under the authority of Head, Sub-Division.

\subsection{Clause 8-Management System requirements}

The implementation of ISO/IEC 17025 is already in place at NPLI for about two decades for the calibration/testing activities. Accordingly, NPLI has opted for option 'A' for transition from 2005 to 2017 and also for implementation of ISO 17034: 2016.

The quality policy and objectives of NPLI are shown in Fig. 4. The management system documents are communicated to, understood by, available to all the personnel involved in calibration/testing/BND activities. These documents are implemented, regularly reviewed and amended, if required, by the authorized personnel.

NPLI has the procedure to control the QMS documents by stamping with a unique marking as defined in Quality Manual. Copies of Quality Manual are distributed as per the distribution list. Revisions/amendments in the quality/document manual are carried out by authorized persons and are circulated as per the distribution list.

Flexibility has been given by the standards to maintain the records either in the form of hard copy and soft copy. However, few records such as copies of certificates/reports, internal audit reports, minutes of meeting (MoM) of steering committee, etc., are maintained in hard copy.

The risks and opportunities associated with implementation of the QMS are taken care by Quality Manager. Similarly, for technical operations, the same is taken care by respective Technical Sub-Division. This includes the consequences and likelihood of the one or more situations such as personnel, environmental conditions (including onsite calibration/testing), electric power supply, calibration/ test/BND (development/production) method, recommendation period of certificates issued, equipments, storage and handling of calibration/test items, uncertainty reported, decision rule (wherever applicable), opinions and interpretations (wherever expressed), transportation of reference standard during on-site calibration/testing, etc., to prevent and mitigate the undesired impacts and potential failures in respective activity. However, as the flexibility is provided in the standard, presently, the documentation of risks and opportunities management process is kept optional.

The inputs from internal audit findings, customer and personnel feedback, complaints, results of international inter-comparisons, risk assessment, etc., are analysed and are discussed in steering committee for continuously improving the effectiveness of QMS. The feedback mechanism from the customers is maintained and analysed by CFCT for improving the customer service.

Whenever nonconformity is identified, necessary action is taken as per laid down procedure to eliminate or mitigate
Fig. 4 Quality policy and objectives of CSIR-NPL (NPLI)

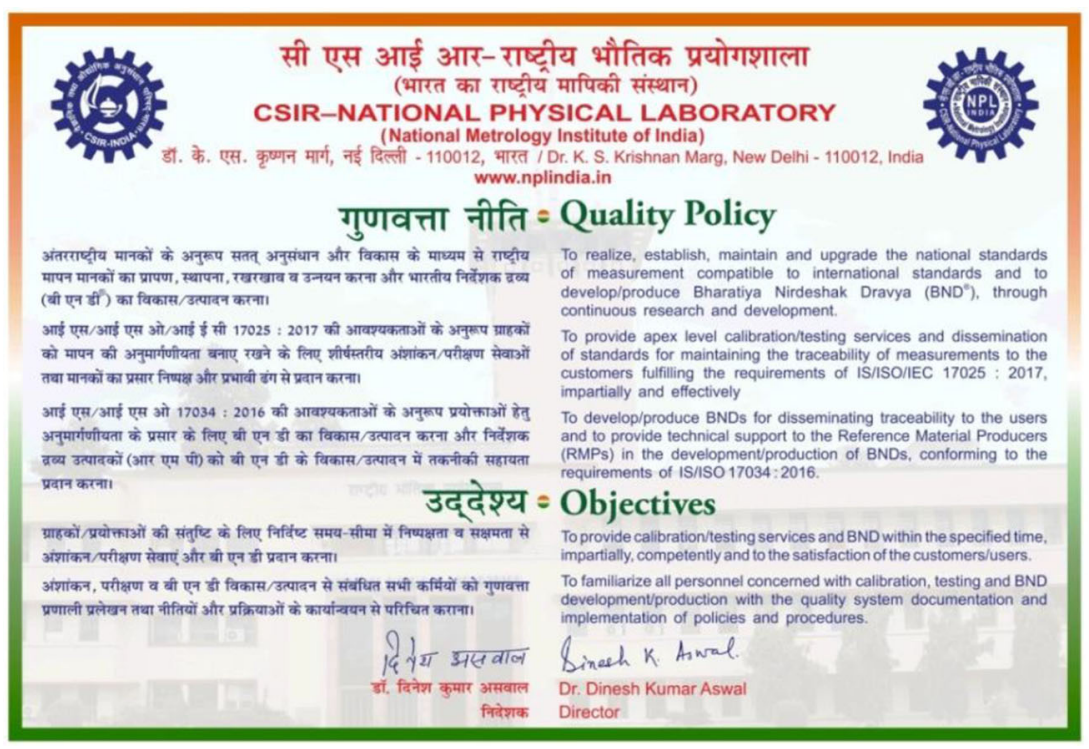


it. In case evaluation indicates that the non-conformance could recur, necessary corrective actions are taken.

NPLI has adequate number of qualified Assessors for performing internal audits of its own. Some of the Scientists and Technical Officers who perform the internal audits are also Lead/Technical Assessors of National Accreditation Board for Testing and Calibration Laboratories (NABL) (Accreditation Body of India) for one of or both the standards. As per the policy of NPLI, internal audits are conducted once in a year. The auditors are selected as per the guidelines of ISO 19011 [18]. Internal audits are conducted following the laid down procedure of QMS.

The activities covered under QMS are reviewed annually by the Steering Committee chaired by the Director to ensure the continuing suitability, adequacy and effectiveness, policies and objectives of the system. The agenda of the Steering Committee meetings includes the requisites mentioned in the standards. The outcome from the Steering Committee meetings is recorded, communicated to the concerned for necessary actions and is followed up by QMS.

\section{Document structure of NPLI}

The QMS related documents of NPLI are three level documents as illustrated in Fig. 5a based on ISO/IEC 17025: 2017 and in Fig. 5b based on ISO 17034: 2016. These three level documents are divided into two parts, i.e., Quality Manual and Document Manual.

The Quality Manual consists of various policies, objectives and procedures of NPLI pertaining to metrological activities. This is the apex level document (Level 1) and contains various formats/guidelines to prepare Document Manual in the respective Sub-Divisions.

The Document Manual (Level 2) is prepared by respective Sub-Division consisting of various documents/ procedures as per the formats/guidelines given in quality manual. There are total 10 documents (Document \# 1 to 10 are identified for calibration/testing activities and Document \# 1A to 10A are identified for BND activities) based on which, document manuals are prepared. The glimpses of 10 documents by numbers and corresponding titles are shown in pictorial form in Fig. 6a for calibration/testing activities based on ISO/IEC 17025: 2017 and in Fig. 6b for BND activities based on ISO 17034: 2016. As shown in organization structure given in Fig. 3, QMS is also an independent Sub-Division. Therefore, apart from preparation of quality manual, it prepares document manual also based on guidelines/formats given in quality manual.

All the relevant technical and management records (Level 3) are maintained by each Sub-Division/Activity.

\section{Conclusion}

For improving quality infrastructure of the country, QMS of NMI of that country should be strong. In this direction, being NMI of India and signatory to CIPM MRA, NPLI has been maintaining QMS as per ISO/IEC 17025 in the metrological activities for the last two decades. NPLI has undergone 130 international inter-comparisons so far such as key/supplementary/bi-lateral comparisons as pilot laboratory or participating laboratory. NPLI has successfully

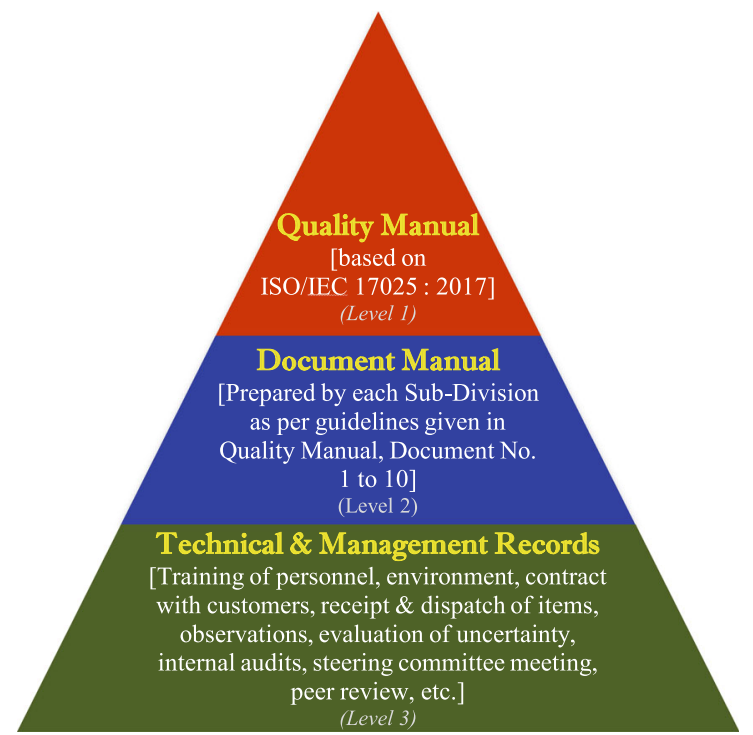

(a)

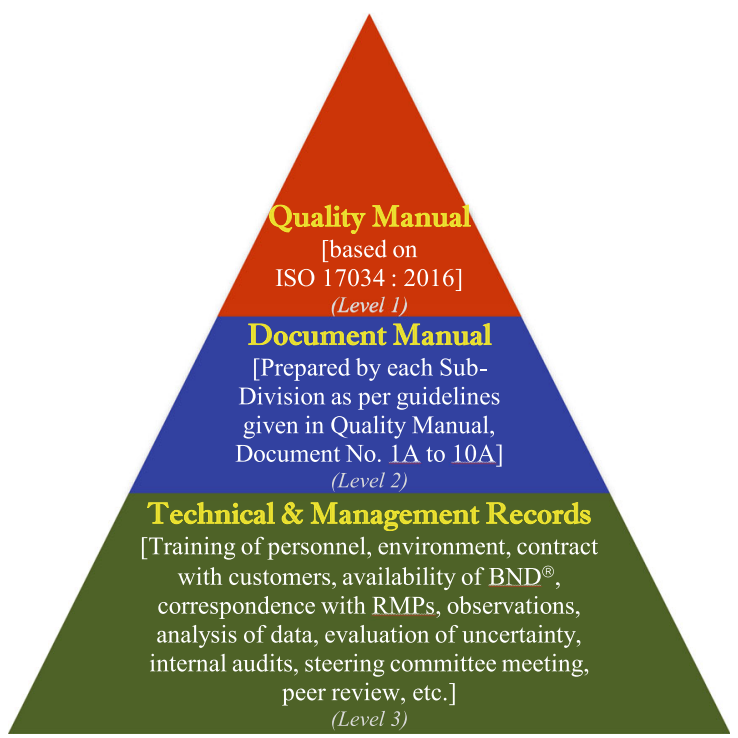

(b)

Fig. 5 Document structure a based on ISO/IEC 17025: 2017 and b based on ISO 17034: 2016 


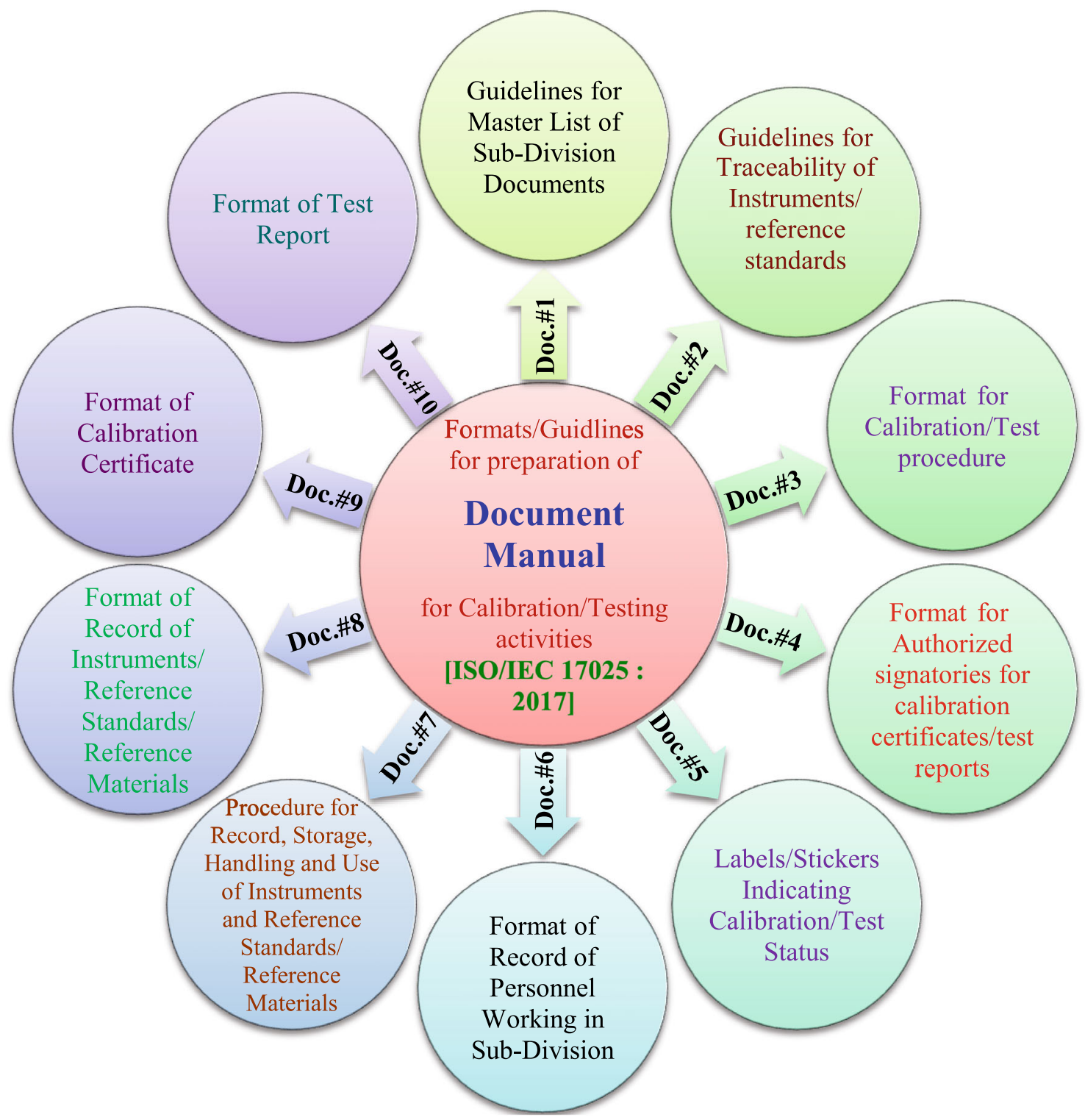

Fig. 6 a Formats/Guidelines for preparation of Document Manual for Calibration/Testing activities based on ISO/IEC 17025: 2017 b Formats/ Guidelines for preparation of Document Manual for BND activities based on ISO 17034: 2016

undergone peer reviews through APMP based on ISO/IEC 17025: 2005 and registered 236 CMCs in various technical parameters in BIPM KCDB. NPLI has also developed/ produced number of BNDs in recent time and 101st BND was released on the occasion of its 75th Foundation day celebration on 4th January 2021.

For the transition of QMS of ISO/IEC 17025 from 2005 to 2017 for calibration/testing activities and to adopt ISO 17034: 2016 for BND activities, NPLI for the first time prepared integrated quality manual. The quality manual contains various policies, objectives and procedures addressing all the requirements of both the standards and also fulfilling the Government of India and CSIR norms. Document manuals, based on formats/guidelines provided in quality manual, are prepared by all the Sub-Divisions covered under QMS. Effectiveness of the QMS is evaluated through internal audits and Steering Committee meeting. NPLI has completed the transition to ISO/IEC 17025: 2017 and implemented ISO 17034: 2016 in October 2020.

NPLI has completed the on-site Peer Review of Quality System of 23 Sub-Divisions covered under QMS in November 2020. The peer review report is under APMP review process. International technical peer reviews of various parameters through APMP are under process for maintaining existing CMCs and its improvement as well as adding new CMCs. 


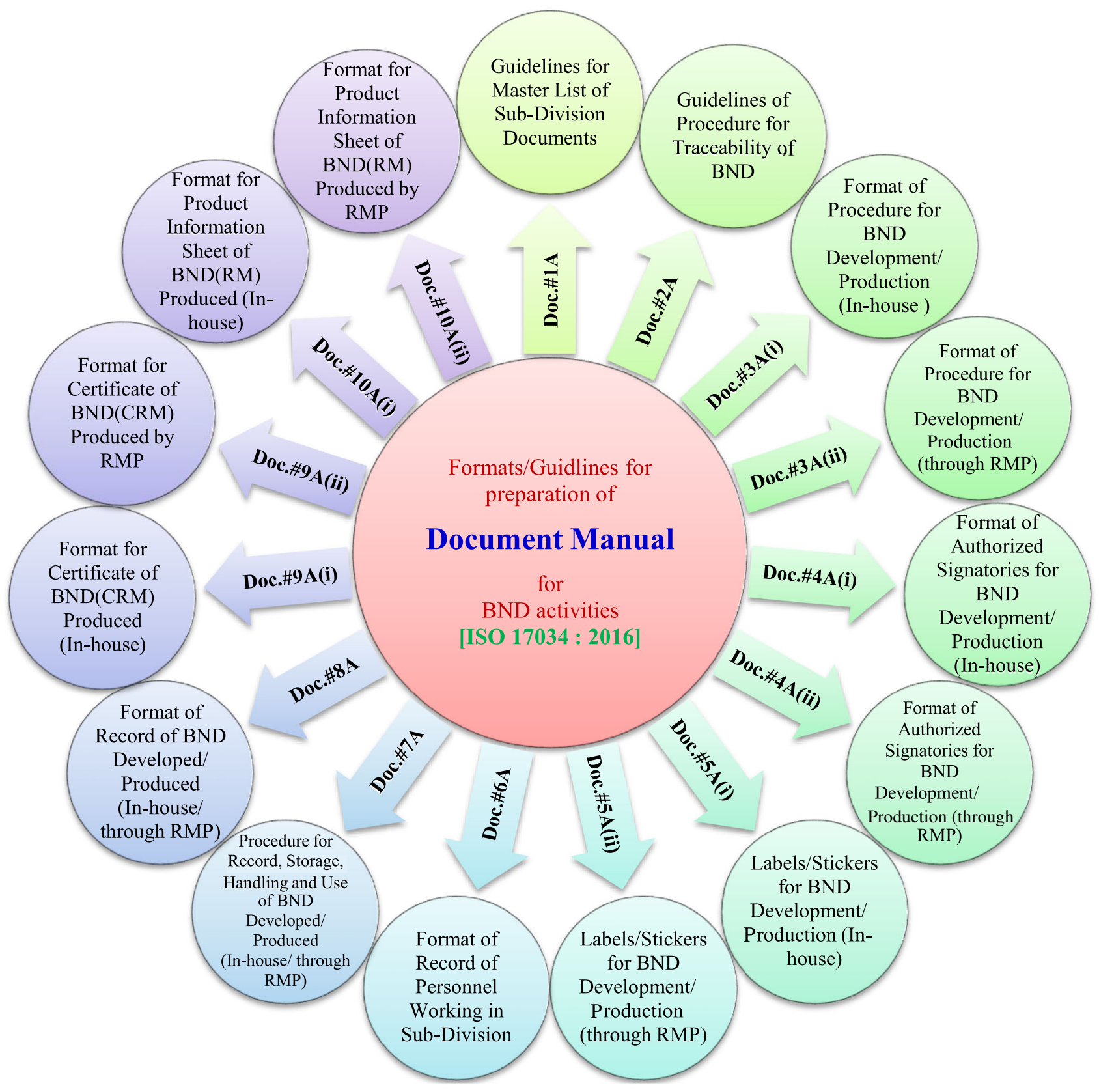

Fig. 6 continued

NPLI is supporting BARC for establishing QMS based on ISO/IEC 17025: 2017 and for international peer review to get the CMCs registered on ionizing radiation in BIPM KCDB for improving quality infrastructure of the country in this area.

Government of India has designated NPLI as a national verification agency for certifying instruments and equipment for monitoring emissions and ambient air such as Continuous Ambient Air Quality Monitoring Station (CAAQMS) and Online Continuous Emission Monitoring Systems (OCEMS), conforming to ISO/IEC 17025: 2017 and ISO/IEC 17065: 2012. Quality Manual based on the requirements of ISO/IEC 17065: 2012 is under preparation and will be implemented soon.

Acknowledgements Authors would like to convey their sincere thanks and appreciation to all the committee members (Anil Kumar, Sanjay Yadav, S. S. K. Titus, Saood Ahmad, Shankar G. Aggarwal, N. Vijayan for ISO/IEC 17025: 2017 and Nahar Singh, S. Swarupa Tripathy for ISO 17034: 2016) for their support and contributions in preparation of quality manual. Authors would like to further extend their sincere thanks to all the Head, Divisions and Head, Sub-Divisions, scientists, staff members for their remarks/suggestions for improvement of quality manual and preparations of document 
manuals in their respective Sub-Divisions. Authors also express their thanks to all the internal auditors for their support in implementation process. Last but not least, authors are also thankful to all the past quality managers and implementation committee members for applying their exclusive ideas in harmonization of documentation process throughout the laboratory.

\section{References}

[1] JCRB 42 resolutions and actions, Resolution 42/1.

[2] ISO/IEC 17025: 2017, General requirements for the competence of testing and calibration laboratories.

[3] ISO 17034: 2016, General requirements for the competence of reference material producers.

[4] Dinesh K. Aswal, Chapter 1, Introduction: Metrology for all people for all time, In: D. K. Aswal (ed.), Metrology for Inclusive Growth of India, pp 1-36, https://doi.org/10.1007/ 978-981-15-8872-3_1.

[5] Sanjay Yadav, Goutam Mandal, Dilip D. Shivagan, Parag Sharma, Afaqul Zafer and Dinesh K. Aswal, Chapter 2, International harmonization of measurements-Part I: International measurement system, In : D. K. Aswal (ed.), Metrology for Inclusive Growth of India, pp, 37-82, https://doi.org/ 10.1007/978-981-15-8872-3_2.

[6] Sanjay Yadav, Goutam Mandal, Dilip D. Shivagan, Parag Sharma, Afaqul Zafer and Dinesh K. Aswal, Chapter 3, International harmonization of measurements-Part II: International and National dissemination mechanisms, In : D. K. Aswal (ed.), Metrology for Inclusive Growth of India, pp, 83-143, https://doi.org/10.1007/978-981-15-8872-3_3.

[7] https://www.bipm.org/en/worldwide-metrology/metre-conven tion, Accessed on $20^{\text {th }}$ March 2021.
[8] https://www.bipm.org/en/cipm-mra, Accessed on 20th March 2021.

[9] https://www.bipm.org/en/worldwide-metrology/regional, Accessed on 20th March 2021.

[10] Legal Metrology, Department of Consumers Affairs, New Delhi, https://consumeraffairs.nic.in/sites/default/files/uploads/legalmetrology-acts-rules/stdrules-compressed_0.pdf, Accessed on 20th March 2021.

[11] https://www.nplindia.in, Accessed on 20th March 2021.

[12] http://apmpweb.org/about/members.php, Accessed on 20th March 2021.

[13] D. K. Aswal, Quality infrastructure of India and its importance for inclusive national growth. Mapan-J. Metrol. Soc. India, 35 (2020) 139-150. https://doi.org/10.1007/s12647-020-00376-3.

[14] APMP-QS2(V.2.0), APMP guidelines for accepting a quality system (V.2.0 WD2), approved in 2010.

[15] APMP Guidelines for on-site peer reviews/assessments under unexpected circumstance due to COVID-19, Version 1.1, published on 1st May, 2020.

[16] Memorandum of Understanding for Scientific collaboration Between CSIR-National Physical Laboratory (CSIR-NPL), New Delhi-110 012 (National Metrology Institute of India) and Bhabha Atomic Research Centre (BARC), Mumbai-400 085, Maharashtra (Designated Institute for Ionizing Radiation).

[17] https://www.nplindia.in/skill-initiative, Accessed on 20th March 2021.

[18] ISO 19011: 2018, Guidelines for auditing management systems.

Publisher's Note Springer Nature remains neutral with regard to jurisdictional claims in published maps and institutional affiliations. 